\title{
Nodular Bartholin Gland Hyperplasia
}

National Cancer Institute

\section{Source}

National Cancer Institute. Nodular Bartholin Gland Hyperplasia. NCI Thesaurus. Code C128241.

Nodular proliferation of normal Bartholin gland tissue and ducts. 